\section{Allergy to a Garlic Lectin in an Infant After the First Intake: Difficulties Identifying the Route of Sensitization}

González-de-Olano $\mathrm{D}^{1}$, Barra-Castro $\mathrm{A}^{1}$, Riaño-Avanzini $\mathrm{T}^{1}$, Pastor-Vargas $\mathrm{C}^{2, *}$, Bartolomé $\mathrm{B}^{3, *}$

${ }^{1}$ Department of Allergy, Hospital Universitario Ramón y Cajal, Madrid, Spain

${ }^{2}$ Department of Immunology, IIS-Fundación Jiménez Díaz, UAM, Madrid, Spain

${ }^{3} R+D$ Department, Roxall, Bilbao, Spain

*Both authors contributed equally to the manuscript and should be considered senior authors

J Investig Allergol Clin Immunol 2018; Vol. 28(4): 253-254 doi: $10.18176 /$ jiaci.0245

Key words: Allergy. Garlic. Infant. Lectin. Sensitization.

Palabras clave: Alergia. Ajo. Lactante. Lectina. Sensibilización.

Food allergy is estimated to affect around 5\% to $10 \%$ of infants and young children in developed countries [1]. Allergic reactions to garlic are not common. In children they are exceptional. Garlic (Allium sativum) belongs to the Amaryllidaceae family and the onion (Allium) genus. It is closely related to shallot, leek, asparagus, and chive. It is widely used in cooking as a natural flavoring and as a natural medicine with many useful properties. Garlic is a respiratory sensitizer that can cause occupational allergy [2,3], a potent contact allergen [2], and a food allergen [4-6]. The only clinically relevant allergen identified to date is alliinase [4], although other proteins have been suggested as possible allergens [6]. We present a case of IgE-mediated allergy to garlic in an infant with results suggesting lectin as the relevant allergen.

A 9-month-old infant experienced itchy erythema affecting the ear, trunk, and groin, along with cough (normal pulmonary auscultation) within minutes after the accidental intake of a homemade garlic sauce. She was still breastfeeding and had never eaten this food before (her mother had) or any other food belonging to the Amaryllidaceae family, with the exception of zucchini, which she tolerated well. The patient and her parents did not have atopic dermatitis or any additional atopic background.

A raw garlic extract (GE) was prepared by homogenization in phosphate-buffered saline $(16 \% \mathrm{wt} / \mathrm{vol})$, dialyzation, and lyophilization (Roxall). The protein content of the extract (wt/wt) was 3\% according to Bradford [7]. Skin prick tests to commercial common aeroallergens-pollens, dust mites, molds, dander, and peach and pollen profilin (Pho d 2) (ALK
Allergologisk Laboratorium A/S) - were negative (wheal, $<3 \mathrm{~mm}$ ). The wheal produced by prick-by-prick testing with garlic was $10 \mathrm{~mm}$. Prick-by-prick with onion, chive, leek, zucchini, and asparagus were all negative. Specific $\operatorname{IgE}$ (sIgE) (Thermo Fisher) to garlic was $3.15 \mathrm{kU} / \mathrm{L}$ (from a total $\mathrm{IgE}$ of $32 \mathrm{kU} / \mathrm{L}$ ), and $\operatorname{sgE}$ against both onion and asparagus was $<0.1 \mathrm{kU} / \mathrm{L}$. The garlic extract was analyzed using SDS-PAGE, which revealed protein bands ranging from $55 \mathrm{kDa}$ to $4 \mathrm{kDa}$. SDS-PAGE IgE immunoblotting assays with the patients' serum were performed under reducing and nonreducing conditions (with and without 2-mercaptoethanol, respectively) and revealed IgE-reactivity with an apparent molecular weight of approximately $8.5 \mathrm{kDa}$ and $9 \mathrm{kDa}$ under nonreducing conditions, and a faint band of approximately $9 \mathrm{kDa}$ under reducing conditions (Figure). Both protein bands detected without 2-mercaptoethanol were manually excised from the gel, digested with trypsin, and analyzed by matrixassisted laser desorption/ionization time of flight and liquid chromatography coupled to tandem mass spectrometry (MC/

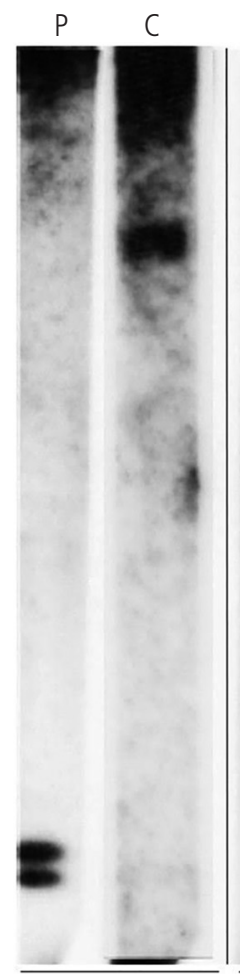

$(-)$

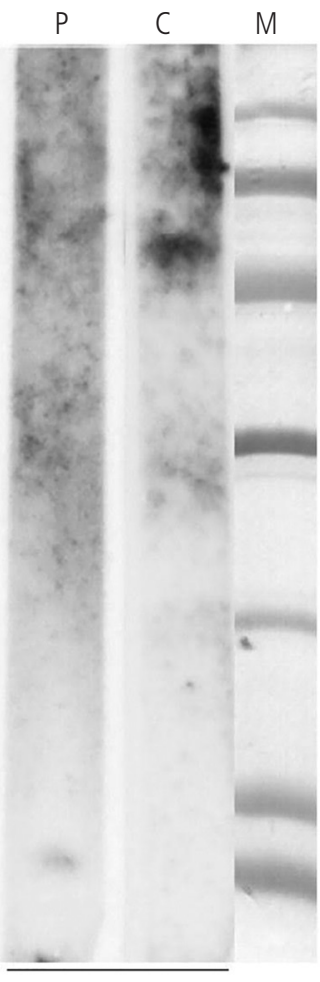

$(+)$ $\underline{k D a}$

97.0

66.0

45.0

30.0

20.1

14.4
Figure. Identification of IgE-binding proteins in the raw garlic extract. $P_{i}$ SDS-PAGE IgE immunoblotting with the patient's serum. C, SDS-PAGE IgE immunoblotting with control sera (pool of sera from nonatopic individuals). (-), without 2-mecaptoethanol (nonreducing conditions) $(+)$, with 2-mecaptoethanol (reducing conditions). M, molecular weight marker. 
MC). Proteins were identified by searching a nonredundant protein sequence database (National Center for Biotechnology Information) using the Mascot program (http://www. matrixscience.com). When compared with the databases, the analysis of the resulting peptides by MS or MS/MS revealed lectin fragments. In order to identify the possible route of sensitization, we asked the mother to collect her breast milk after consumption of garlic, since breast milk has been reported to be a probable first gateway for contact with allergens in infants [8]. We performed prick-by-prick testing with breast milk samples extracted 6 hours, 12 hours, and 24 hours after the mother's intake of $10 \mathrm{~g}$ of garlic, with negative results for all the samples. SDS-PAGE IgE immunoblotting assays with breast milk showed no IgE-reactivity (results not shown).

Lectins are carbohydrate-binding proteins, which are highly specific for sugar moieties. They play numerous roles in biological recognition phenomena involving cells, carbohydrates, and proteins. Lectins are ubiquitous in nature and are found in many foods. Besides their utility in medical research and their use as a biochemical tool, lectins have also been described as heat-labile allergens of various foods, especially legumes and wheat [9].

Allergy to garlic takes the form of contact dermatitis [2] and as occupational allergy and asthma in mill workers exposed to high levels of aerosolized spices [2,3]. Adverse reactions after ingestion of garlic have also been reported [4]. Alliinase is a major garlic allergen [4], and additional proteins have been suggested as possible novel allergens in garlic clove (enolase [twice], high-molecular-weight and low-molecular-weight glutenin, $\alpha$-amylase inhibitor, triosephosphate isomerase, starch synthase, and lectin fragments), although no clinically relevant allergy to any of those allergens has been found [6].

We report a case of allergy to garlic in a 9-month-old breastfeeding infant who had never eaten garlic before. One of the most striking contributions of our study is the fact that the infant became allergic to a food rarely reported to be allergenic and that she had never eaten before. Furthermore, lectin was demonstrated to be the relevant allergen. Unfortunately, the route of sensitization to garlic remains unclear; sensitization through breastfeeding cannot be ruled out even though the study carried out with breast milk showed no positive results, as the in vitro and in vivo techniques performed might not be sufficiently sensitive enough. Besides breastfeeding, it has been argued that sensitization may occur during pregnancy, and detection of major food allergens in amniotic fluid has also been reported [10]. Since the patient was allergic to lectin fragments, suggesting exposure to a fragment of the protein, the authors hypothesized that any of the abovementioned routes could be involved. Inhaled, cutaneous, and other possible sensitization routes should be also taken into account. Nevertheless, in many of the occupational cases reported, the patient usually tolerated the food. The patient we report did not and was later exposed to steam from steamed garlic with no reaction or damaged skin associated with atopic dermatitis. IgE-mediated disease is not frequent in contact dermatitis [3]. Although the immune mechanisms involved in allergic reactions are not always clear, physicians should always bear in mind the possibility of unexpected reactions regardless of age or circumstances and try to identify the causes in order to implement counselling sessions, treatments, or prevention strategies.

\section{Funding}

This work was supported by grants from the Instituto de Salud Carlos III and the thematic network and cooperative research centers ARADyAL RD16/0006/0013 and RD16/0006/0022, co-supported by FEDER grants.

\section{Conflicts of Interest}

The authors declare that they have no conflicts of interests.

\section{References}

1. Koplin JJ, Peters RL, Allen KJ. Prevention of Food Allergies. Immunol Allergy Clin North Am. 2018;38(1):1-11.

2. van $\operatorname{der}$ Walt $A$, Lopata $A L$, Nieuwenhuizen $N E$, Jeebhay MF. Work-related allergy and asthma in spice mill workers - The impact of processing dried spices on lgE reactivity patterns. Int Arch Allergy Immunol. 2010;152(3):271-8.

3. Añibarro B, Fontela JL, De La Hoz F. Occupational asthma induced by garlic dust. J Allergy Clin Immunol. 1997;100(6 Pt 1):734-8.

4. Kao SH, Hsu CH, Su SN, Hor WT, Chang T WH, Chow LP. Identification and immunologic characterization of an allergen, alliin lyase, from garlic (Allium sativum). J Allergy Clin Immunol. 2004;113(1):161-8.

5. Ma S, Yin J. Anaphylaxis induced by ingestion of raw garlic. Foodborne Pathog Dis. 2012;9(8):773-5.

6. Treudler R, Reuter A, Engin AM, Simon JC. A Case of Anaphylaxis After Garlic Ingestion: Is Alliinase the Only Culprit Allergen? J Investig Allergol Clin Immunol. 2015;25(5):374-5.

7. Bradford MM. A rapid and sensitive method for the quantification of microgram quantities of protein utilizing the principles of protein-dye-binding. Anal Biochem. 1976;72:248-54.

8. Pastor-Vargas C, Maroto AS, Díaz-Perales A, Villaba M, Casillas Diaz N, Vivanco F, et al. Sensitive detection of major food allergens in breast milk: first gateway for allergenic contact during breastfeeding. Allergy. 2015;70(8):1024-7.

9. Barnett $D$, Howden ME. Lectins and the radioallergosorbent test. J Allergy Clin Immunol. 1987;80(4):558-61.

10. Pastor-Vargas C, Maroto AS, Díaz-Perales A, Villalba $M$, Esteban V, Ruiz-Ramos $M$, et al. Detection of major food allergens in amniotic fluid: initial allergenic encounter during pregnancy. Pediatr Allergy Immunol. 2016;27(7):716-20.

Manuscript received January 25, 2018; accepted for publication February 21, 2018.

David González-de-Olano Department of Allergy Hospital Universitario Ramón y Cajal Cta. Colmenar Viejo km 9,100 28034 Madrid, Spain

E-mail: dgolano@yahoo.es 